\title{
Simplified Method of Discharge Measurement for Micro-Hydropower Capacity Assessment: A Case Study for a Small-Scale Agricultural Irrigation Canal
}

\author{
Jibsam F. Andres ${ }^{1,3, *}$, Michael E. Loretero \\ ${ }^{1}$ Engineering Graduate Program, School of Engineering, University of San Carlos, Talamban Campus, Cebu City, 6000, Philippines \\ ${ }^{2}$ Department of Mechanical Engineering, University of San Carlos, Talamban Campus, Cebu City, 6000, Philippines \\ ${ }^{3}$ College of Engineering and Technology, Western Philippines University, Aborlan, Palawan 5302, Philippines
}

Received March 26, 2020; Revised May 20, 2020; Accepted May 27, 2020

Copyright $\odot 2020$ by authors, all rights reserved. Authors agree that this article remains permanently open access under the terms of the Creative Commons Attribution License 4.0 International License

\begin{abstract}
Discharge flow rates were used to assess and determines the hydropower capacity of water source. It is known that the procedure for discharge measurement using common methods requires multiple parameters. These parameters were measured respectively to determine the water power. In reality, water flow may not the same in the succeeding times. Therefore, parameters should be measured simultaneously will give a more relevant water profile assessment. Likewise, these common methods are not feasible during heavy water flow. With these, the study develops two things; 1.) the adjustment factors of different common methods in measuring water discharge, and 2.) the simplified method of weir method. The simplified approach of weir method measures the water discharged by measuring the overflow head of water above the weir crest. A simultaneous data observation was performed in the experiment to develop the simplified approach of weir method and derived adjustment factors of each method. The result shows that 3-point method of current flow-meter and float method gives almost the same as true discharge value. The true discharge value of the simplified method of weir method is multiplied by the adjusted factor equal to 0.81 .
\end{abstract}

Keywords Irrigation Canal, Hydropower Capacity, Adjustment Factors, Discharge Measurement

\section{Introduction}

Hydro energy generation is renewable and is sustainable and could generate clean electricity. Studies show that the generation of electricity through renewable energy reduces carbon dioxide emission on earth, which results to the "greenhouse effect" as well as the "global warming". Renewable energy such as solar, wind, biomass, wave, geothermal, and hydro are indigenous sources of energy which could be utilized especially in the countries like the Philippines. The Republic Act or RA 9513 better known as "An Act Promoting the Development, Utilization and Commercialization of Renewable Energy Resources and for other Purposes" is enforced in the Philippines. RA 9513 shows the great importance of the utilization of renewable energy in the country. The hydropower system generates energy through the use of falling water in a river or stream. The flow of falling water creates kinetic energy to the turbines, which makes the turbine blades an alternator. Falling water is converted to an electrical power $\mathrm{P}$ given by the equation 1 [1-5], where, $\alpha$ is the overall efficiency of turbine and generator, $\rho$ is the water density $\left(1000 \mathrm{~kg} / \mathrm{m}^{3}\right)$, $g$ is the gravity $(9.81 \mathrm{~m} / \mathrm{s}), H$ is the head of the falling water and $Q$ is the discharge of water in $\mathrm{m}^{3} / \mathrm{s}$. The electrical power of a stream or river varies and directly proportional to the volume of water in cubic meters per second described as flow rate, $Q$.

$$
P=\alpha \rho g Q H, \text { watt }
$$

Thus, flow rate also is a product of the velocity of water and the cross-sectional area of the stream described by the equation $2[2,4]$.

$$
Q_{\text {mean }}=\left(V_{\text {mean }}\right)(A)
$$

where, $Q_{\text {mean }}$ is the mean flow rate, $V_{\text {mean }}$ is the mean velocity of water and $A$ is the cross-sectional area of the stream. Flow rate $Q$ of water varies with many variations within the considered time and could be affected by the methods in determining the flow rate or discharge.

Though there is a legal or even financial support of the Philippine government on renewable energy, still the country is problematic in terms of electrical energy and 
has a projected energy crisis. Philippines is an agricultural country and therefore the establishment of agricultural irrigations has existed for decades. With it, further developments of these irrigation projects were continuously included as priority of the government and are implemented.

Existing irrigation canals could be a source of energy. In determining the hydropower capacity of water resources specifically those existing agricultural irrigation canals, it involves the methods of discharge measurements. Common methods of discharge measurements are the weir, float, volumetric (bucket method), and using current flow meter instruments. A method using a current meter could be divided into another four methods: the 3-point, 2-point, 1-point, and surface method.

There are factors that are considered to have an efficient estimate of assessing water profile and hydropower capacity of the water source. Such as correction factor $\mathrm{C}$ and discharge coefficient $\mathrm{c}[1,2]$. The correction factor $\mathrm{C}$ is recommended to consider in the computation of the water discharge using float method. This correction factor $\mathrm{C}$, varies with the different type of canal or stream where the method was performed. While discharge coefficient $\mathrm{c}$, is required when measuring the water discharge using the weir method and it varies on the overflow head of the water flow, crest's width and crest's height [2].

Among the mentioned factors and variables that affects the water discharge measurement, there were no studies that recommend an adjustment factor of each common method of measuring the water discharge to make the flow rate measured into true discharge. Only that, most of the studies state the advantages and disadvantages of each method. Example is when the current flow meter is used; it is convenient to use, but not economical and is not possible during floods [2].

It is also known that the procedure for discharge measurement using common methods requires multiple parameters and performed respectively to determine the water power. Since in reality, water flow may be not the same during the consecutive measurement of parameters, therefore, the simultaneous measurement is more relevant in assessing water profile. With these, the determination of adjustment factors of each common method was performed as well as the development of simplified weir method.

Except from the volumetric method or bucket method, all other mentioned common methods of discharge measurement require a number of parameters. However, this volumetric method is considered to be complex when large amounts of water volume is to be measured. While on the other hand, rectangular weir method is acceptable as the simplest method if large amount of water is to be measured. But this weir method becomes complex because parameters to compute water discharge cannot be measured simultaneously. An example is that the weir's water head $H$ is measured at a distance 3 to 4 times $\mathrm{H}$ from the overflow point of the canal and above the height of the weir crest which must be 2 to 3 times $H[6,7]$. To make the rectangular weir method simply, the study derived an adjustment factor $A_{f}$ for weir and other common methods considered. In this simplified weir method, the water head $H$, is measured at the overflow point above the weir crest regardless the height of the weir and is adjusted using adjustment factor, $A_{f}$, to be a true discharge value.

The content of this study objects the determination of the adjustment factor of each considered common discharge measurement method. It also includes the daily water discharge of Manaile irrigation for a year-round using simplified weir method. The result of this study shows, the assessed hydropower capacity of small-scale water source specifically, the existing agricultural irrigation and the adjustment factors of simplified weir method, float method, 3-point, 2-point, and 1-point method. As part of the result of the study, the derived adjustment factor of the simplified weir method was used to adjust the daily water profile of the irrigation and then used to compute the hydropower capacity of Manaile irrigation canal. To achieve such results, this study provides discussions and illustrations of all the methods and materials used in the experiment in the study.

\section{Materials and Methods}

Figure 1 below is the paradigm of the methods of the study. The daily water discharge has been a year-round data measured regularly along the rectangular concrete irrigation using the simplified approach of weir method. While the water discharge of different common methods was measured simultaneously using to determine the adjustment factors of each method.

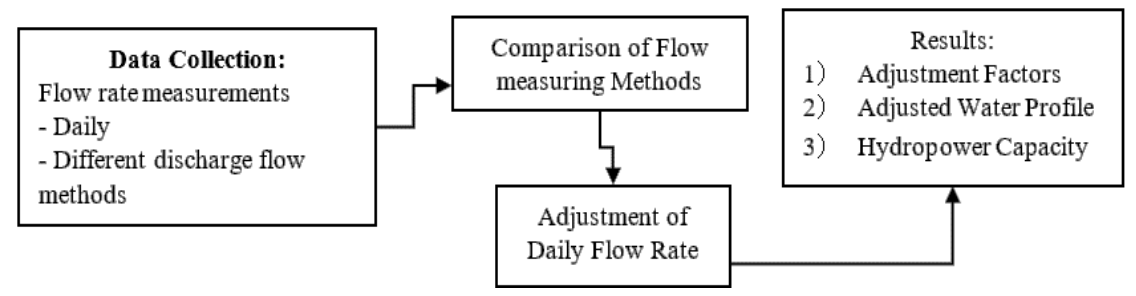

Figure 1. Paradigm of Methodology 


\subsection{Daily Water Discharge}

The daily measurement of flow rates was to determine the power capacity of Manaile irrigation canal and was recorded from March 2015 to February 2016. The existing water gate of the concrete canal was used to categorize as suppressed weir which means that the designated weir width $\mathrm{L}$ is the same as the width of the canal. As illustrated in Figure 2, the overflow head h, was measured above the weir crest once a day. The weir method performed in this study was a simplified approach method. This method simply measures the overflow head above the weir crest installed. Unlike the standard practice of weir method, the overflow head is measured behind and above from the weir crest by a distance proportion to the height of the weir crest $[6,7]$ respectively.

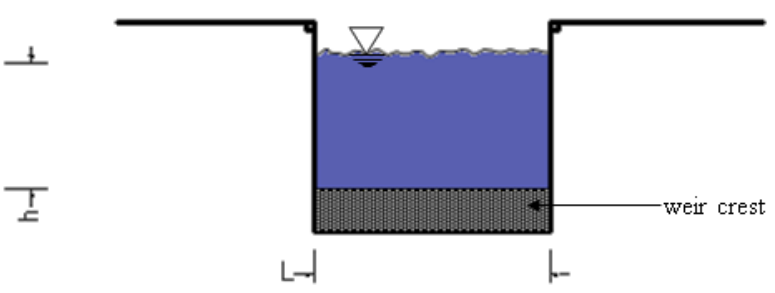

Figure 2. Illustration of Weir Methods Measurements
The 100-meter rectangular concrete canal is located at Manaile irrigation, Narra, Palawan, Philippines. Along this 100-meter rectangular concrete canal, the simultaneous measurement of water discharge was performed as illustrated in Figure 3. This further shows that methods using a current flow meter were measured at the same point. Other methods such as the simplified approach of weir method, volumetric method and float method were designated as shown in Figure 3. Data of each method were taken simultaneously and replicated ten (10) times.

\subsection{Weir Method}

The weir is like an ordinary dam and is a channel obstruction over which the flow must deflect [6-8]. Water discharge $Q$, using weir principle correlates with the gravity and with the blockage height $h$, to which the upstream flow is backed up above the weir elevation. Weir method measures stream discharge by the equation 3 using with discharge coefficient $c$ shown in equation 4 below. In this method, $Q$ is the water discharge, $L$ is the opening width of the weir, $c$ is the discharge coefficient and $h$ is the overflow depth [2,9].

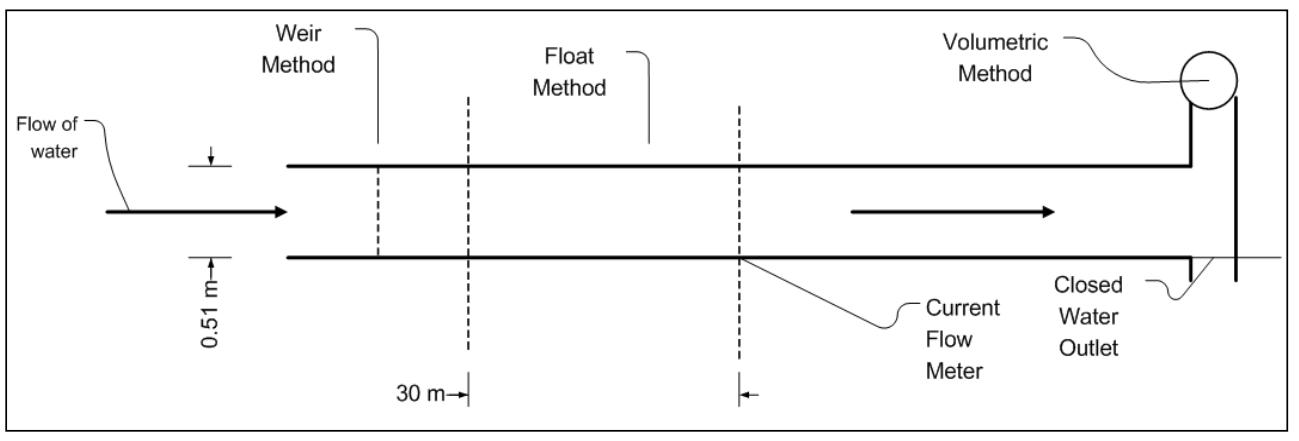

Figure 3. Positioning of simultaneous measurement of different methods

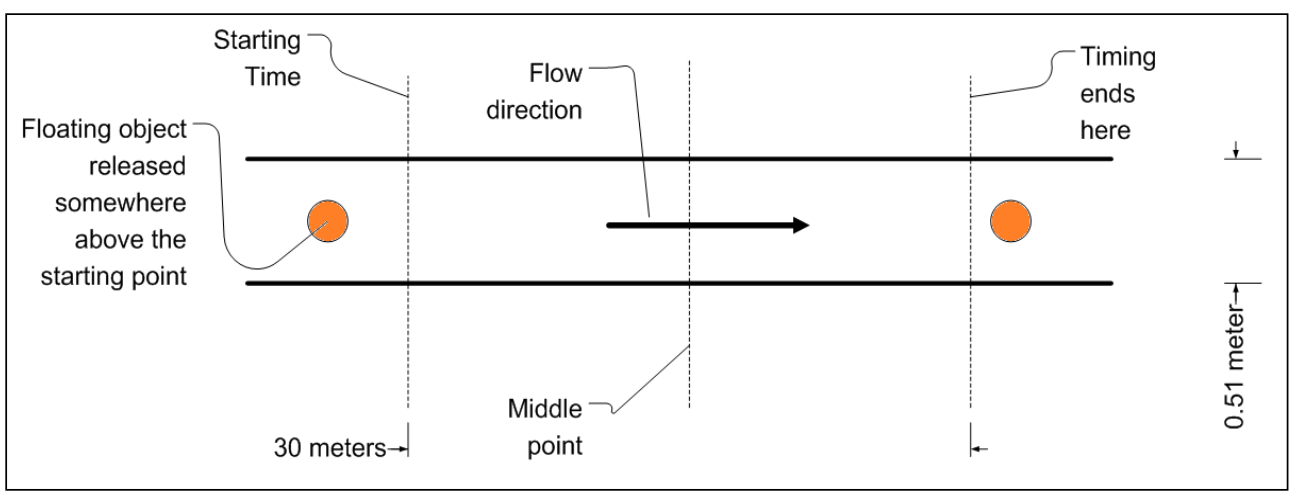

Figure 4. Positions of taking inputs of float method measurement 
Along the 100-meter concrete canal, the data were recorded for the simplified approach weir method. This is by taking the overflow head above the weir crest with the height of 0.135 meters located on the upper part of the canal.

$$
\begin{gathered}
Q=c L h^{1.5} \\
c=1.828\left(1+\frac{0.0012}{h}\right)\left(1-\frac{\left(\frac{h}{L}\right)^{1 / 2}}{10}\right)
\end{gathered}
$$

$Q$ : water discharge $(\mathrm{m} / \mathrm{s})$,

$c$ : weir method discharge coefficient

$L$ : opening width of the weir (m.)

$h$ : overflow depth (m)

\subsection{Measurement Using Float Method}

The water velocity using the float method was performed by measuring the time travelled of the floating material. In this study, orange fruit [10] was used as the floating material along the 30-meter distance $[10,11]$ 100-meter concrete canal as shown in Figures 3 and 4. The 30-meter distance was divided into three (3) parts: the starting point, middle point and ending point. Using equation 5 below, water velocity of float method was computed. Where $v$, is the average velocity from the ten (10) trials of experimental. It is the product of the average time traveled multiplied to the total distance traveled along the 30-meter floating space.

$$
v=t x d
$$

(1)

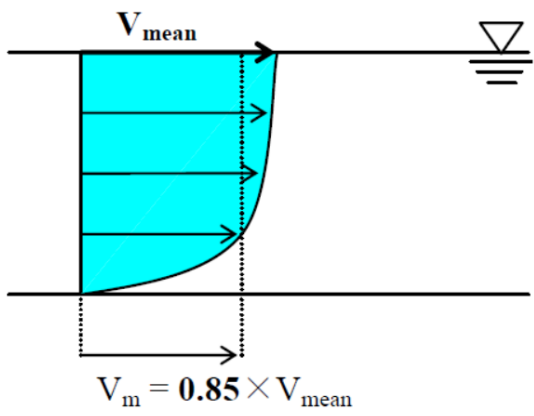

(3)

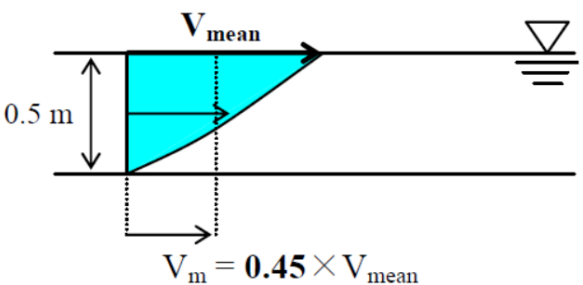

The water discharge $Q$, of float method, is the product of float's velocity and the cross-sectional area of the stream or canal as shown in same Figure 2. It is computed using equations 6 and 7. The cross-sectional area, $A$, of the stream or canal was obtained by taking the width of the stream multiplied to the average depth of the water. The area $A$, is the average area measured from the three (3) points: starting point, middle point and ending point (Figure 4). The same method of computation for the water depth $\mathrm{D}$, which was the average water depth of the three (3) considered points. All parameters for the float method were measured simultaneously and computed using equations 6 and 7.

$$
\begin{gathered}
Q=(C)(v)(A) \\
A=(W)(D)
\end{gathered}
$$

$$
\begin{aligned}
& Q: \text { water discharge }\left(\mathrm{m}^{3} / \mathrm{s}\right) \\
& C: \text { correction factor (Figure } 5) \\
& v: \text { float method's velocity }(\mathrm{m} / \mathrm{s}) \\
& A: \text { area of the stream or canal }\left(\mathrm{m}^{2}\right) \\
& W: \text { width of the stream or canal }(\mathrm{m}) \\
& D: \text { average depth of water }(\mathrm{m})
\end{aligned}
$$

Recommended correction factors for every type of stream or canal were shown in Figure 5 [1,2]. The correction factor 0.45 were considered for the canal where the measurement was performed. The 0.45 factor is in a shallow flow canal, but with concrete channel which the cross-section is uniform and when the shape is rectangular.

(2)

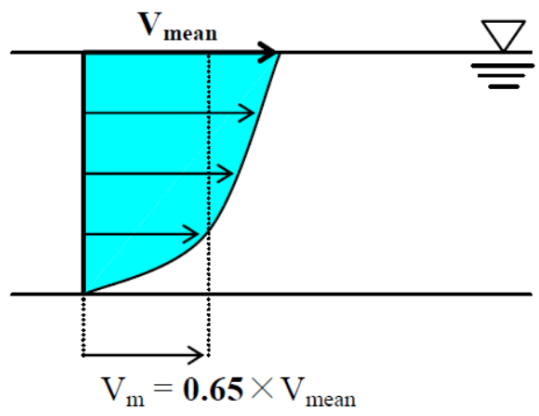

(4)

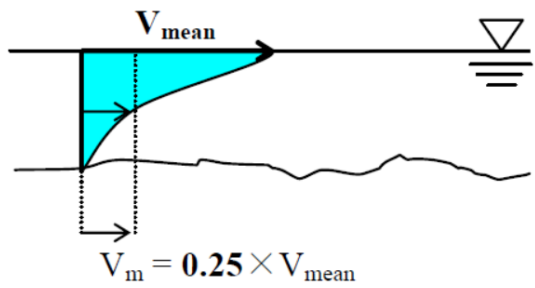

Figure 5. Correction Factors for float method discharge calculation [2] 


\subsection{Flow Rate Measurement Using Current Meter}

The use of current meter instruments claims its accuracy and applicability on any open body of flowing water. This makes to be the most convenient method in measuring flow of water [10]. This method could be divided into four (4) other discharge measurement methods. These are the 3-point, 2-point, 1-point method and surface measuring method $[1,2]$. Discharge measurements using the current flow meter instruments compute the mean velocity of the water by measuring the velocities at a certain percent depth of the stream as illustrated in Figure 6.

The water velocity of a stream at different depth were measured to compute the four methods of discharge measurement using the current meter instrument. These were the water surface velocity and water velocities at $20 \%, 60 \%$ and $80 \%$ depth. Below are the equations 8 to 11 to compute mean velocities of each method using the current meter instrument. Where $V m$ is the mean velocity, $V_{s}$ is the surface velocity and $V_{0.2}, V_{0.6}$, and $V_{0.8}$ are the water velocities at $20 \%, 60 \%$ and $80 \%$ depth respectively $[1,2]$.

3-point measuring method:

$$
V_{m}=0.25\left(V_{0.2}+2 V_{0.6}+V_{0.8}\right)
$$

2-point measuring method:

$$
V_{m}=0.5\left(V_{0.2}+V_{0.8}\right)
$$

1-point Measuring method:

$$
V_{m}=V_{0.6}
$$

Surface measuring method:

$$
V_{m}=0.8\left(V_{S}\right)
$$
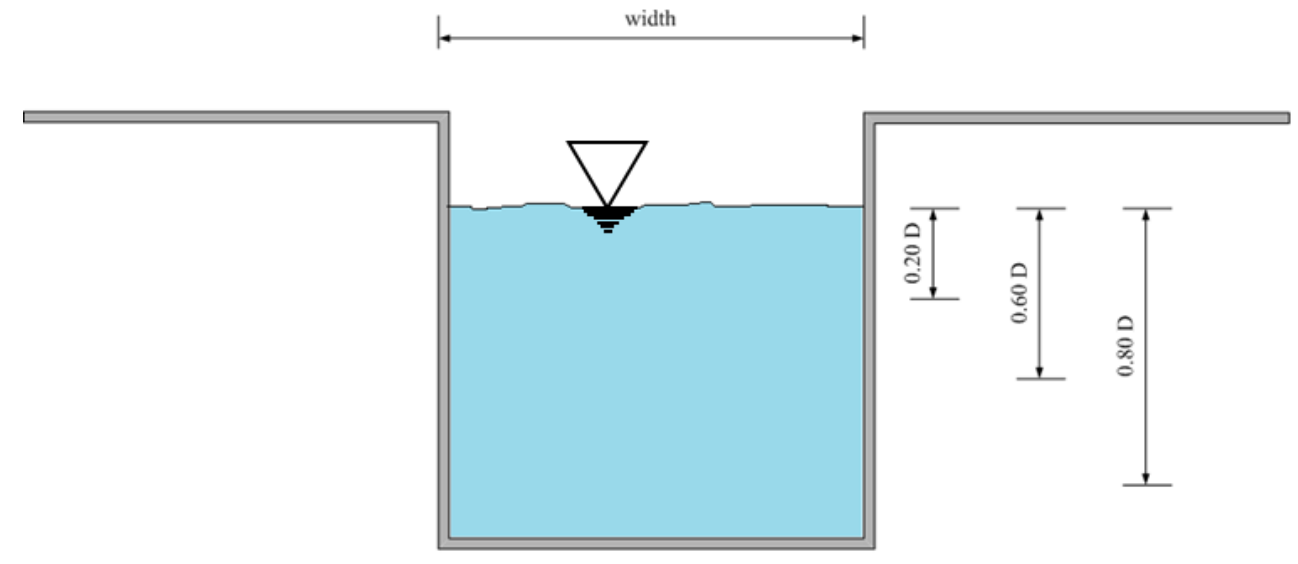

Figure 6. Stream's widths and percent depths for current meter reading
The water discharge using a current flow meter was determined by multiplying the method's velocity to the area $A$, of the stream or canal. The considered area of the stream in each method is determined by measuring the stream width perpendicular to the water flow multiplied by the average depth of water in the section considered. Figure 6 illustrates the percent depth of water in determining water velocity using the current flow meter.

\subsection{Measurement Using Volumetric Method (Bucket Method)}

The volumetric method is also known as the time-volume method or bucket method and is used as the reference for the study. This method takes the time by allowing the water flow to fill the container with a known volume. The measurement of volumetric method was performed using the 200 liters (known volume) plastic drum with a ten (10) inches diameter, polyvinyl chloride conduit (PVC). The PVC pipe was used as the waterway from the canal to the plastic drum. The experiment was performed by allowing the water flow and draining the plastic drum until the ten (10) trials were completed. The time for a known volume of water to be captured in a container such as a bucket was recorded and converted into a flow rate $[2,12,13]$.

Parameters observed in this method were the time $t$ that fills the plastic drum of known volume. Vol. The water discharge $Q$ was computed using the equation 12 . Where, $Q$ as the volumetric method's water discharge $\left(\mathrm{m}^{3} / \mathrm{s}\right), \mathrm{Vol}$ is the known volume of the container $\left(\mathrm{m}^{3}\right)$, and time, $t$ in seconds (s).

$$
\mathrm{Q}=\left(\mathrm{V}_{\mathrm{ol}}\right) /(\mathrm{t})
$$




\subsection{Adjustment Factor of Water Flow Rate Measuring Methods}

Adjustment factors of discharge measurement methods were established by comparing the methods performed in the simultaneous experiment. It was derived using the percent error or percentage error formula, $P E[14,15]$. In this study, the percent error is the difference between a measured or method's value and the established or true value shown in equation 13. Equation 13 could also be arranged into a method's equivalent formula as equation 14. This method's value is also equal to true or established value when it is multiplied by an adjustment factor as shown in equation 15. By the substitution method of equations 14 to equation 15, the formula of adjustment factor, $A f$ was then derived as equation 16 .

The comparison of discharge measurements was also conducted to validate the year-round discharge data and was used for the computation of the water power capacity of the irrigation canal. The data of the four (4) methods using the current-meter, the float method and the weir method were compared to the data of the volumetric method (bucket method). This method was considered as the true and established value in the experiment. The computed value of the adjustment factor $(A f)$ of was then used to adjust the water profile of the Manaile irrigation.

$$
\begin{aligned}
& P E=\left[\frac{\text { Method's Value }- \text { Established Value }_{\text {Established Value }}}{x 100}\right. \\
& \text { Method's Value }=\text { Established Value }\left(\frac{P E}{100}+1\right) \\
& (\text { Method's Value })(A f)=\text { Established Value } \\
& A f=\left[\frac{1}{(P E / 100)+1}\right]
\end{aligned}
$$

\subsection{Water Profile of Irrigation Canal}

The recorded daily water flow discharge of Manaile irrigation from March 2015 to February 2016 was an observed data using the simplified approach weir method. The procedure was a measurement of the overflow head above the crest of the weir. This water flow profile was adjusted by multiplying the weir's adjustment factor $(A f)$ derived from this study. The adjusted daily water discharge was the basis to determine the flow duration curve of Manaile irrigational canal which also the reference for the assessment of hydropower capacity of the irrigation canal.

\subsection{Flow Duration Analysis}

The flow duration analysis is the presentation of flow duration curve. It is by taking all the flow records over the year and placing them with the highest figures on the left and the lower figure placed progressively over to the right.

The flow duration curve is useful in the estimation and calculation of water power that could be generated so that it is possible to calculate the time in a year that certain power levels can be obtained. Computations to plot the flow duration curve and analysis were simulated using the Microsoft EXCEL program. The following are the steps to obtain the flow duration curve of the adjusted water flow rate:

1. Select and arrange chronologically the record of discharge flow.

2. Compute the total number of time intervals in the period of record;

3. Rank discharge by magnitude. This method is by sorting the record of discharge from largest to smallest;

4. Calculate the percent of time that each discharge is equalled or exceeded. This step is to have exceedence of probability which can be calculated by the equation 17 [16],

$$
P=100\left[\frac{M}{(n)+1}\right]
$$

P: probability that a given flow will be equalled or exceeded ( $\%$ of time)

M: ranked position of the water discharge listed. This rank position is equal to the result of step \#3 (rank discharge in magnitude.

$n$ : number of events for period of record

5. Rank discharge and determine the maximum and minimum discharge of the record;

6. Make a class boundary and determine the number of occurrences of each class;

7. From the first class to the upper boundary compute the cumulative number of days of each class;

8. Convert the number of occurrences into a percentage of time; and

9. Graph the flow duration curve showing the water flow versus percent of time discharge is equalled or percent exceeded of the time.

\section{Results and Discussion}

\subsection{Adjustment Factors of Simplified Approach}

The difference in water flow rate of six (6) methods measured simultaneously is shown in Figure 7 below. This figure shows the noticeable regular high discharge value of the simplified approach weir method compared to the other five (5) methods. Taking the volumetric method as the true discharge, the result of experiment shows that the flow rate of simplified approach weir method has the highest flow rate value. While the 3-point method and float method were significantly equal to the true water discharge (Table 1.). The same result was interpreted from the results shown in Figure 8. This result presented in the scatter graph shows that aside from the simplified weir method, all data were closer to the true data.

Table 1 below further shows the adjustment factors of 
each method to true value of water discharge. Though the simplified approach weir method has the highest error, the simplicity and ease to perform this method still can give a true value of flow rate. This is by adjusting the value using the derived adjustment factor. The true value of the measured flow rate using the simplified approach weir method is computed as,

$$
\mathrm{Q}_{\mathrm{T}}=\mathrm{Q}\left(\mathrm{A}_{\mathrm{f}}\right)
$$

where $Q_{T}$ will be the true discharge, $Q$ is the measured flow rate using a simplified approach of weir method using equations 3 and 4 , and $A_{f}$ is the derived adjustment factor of simplified approach weir method equal to 0.81 .

The derived adjustment factors of the other common methods such as methods using current flow-meter, float method and conventional weir method were recommended to be used for the assessment of water discharge. In which, the computed value will be more accurate.

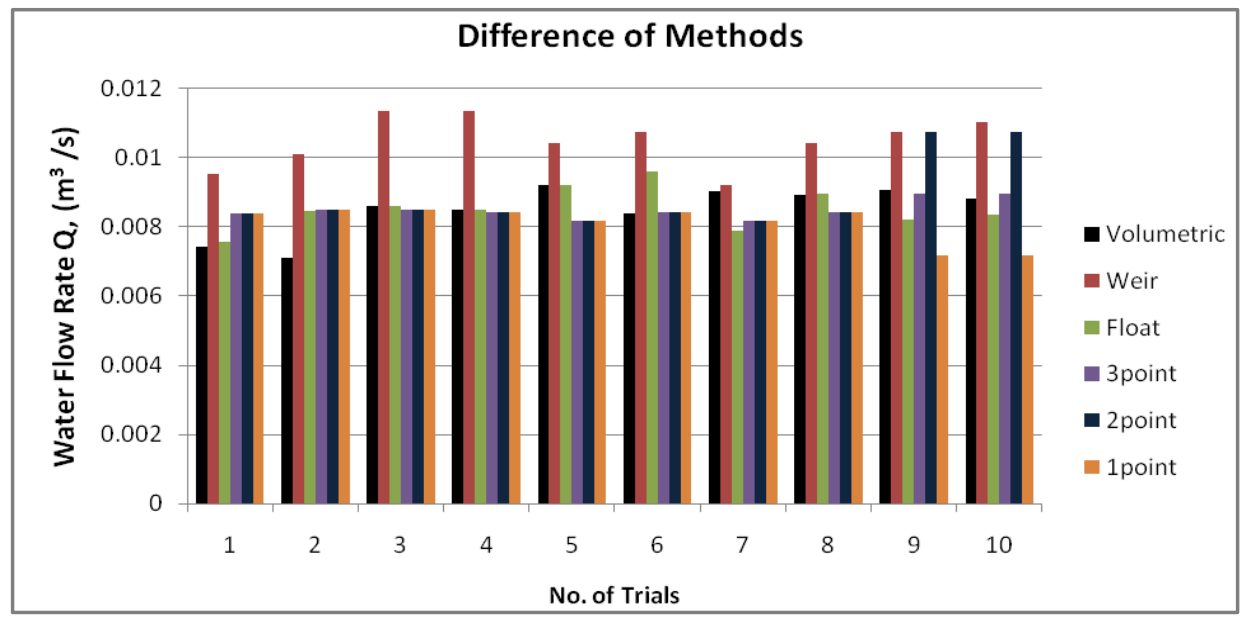

Figure 7. Comparison of flow rate observed simultaneously

Table 1. Summary of different methods' average flow rate, percent error, adjustment factor

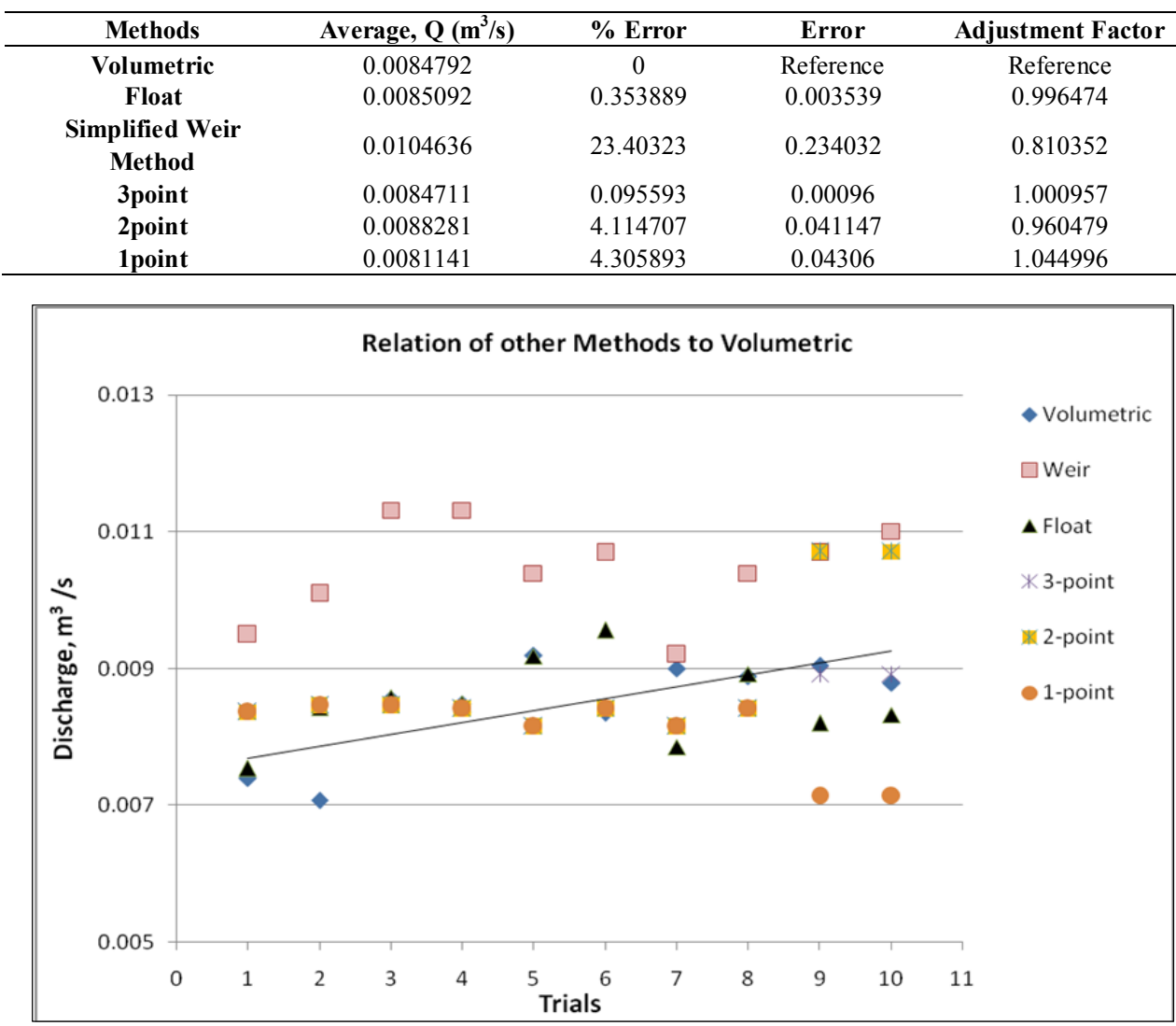

Figure 8. Scatter plot presentation of the relations of methods for water flow measurement 


\subsection{Water Profile of Manaile Irrigation Canal}

Figure 9 shows the daily water profile of the Manaile irrigation canal from the months of March 2015 to April 2016. The red lines are the raw data of daily water discharge measured using the simplified approach weir method while blue lines are the adjusted water discharge using the adjustment factor, $A_{f}=0.810$ (Table 1). It further shows that the water discharge was adjusted and reduced by $23.40 \%$.
The new and adjusted water profile shows that the months of March and April recorded to have flow rate less than $4.0 \mathrm{~m}^{3} / \mathrm{s}$. The adjusted water profile draws a new minimum and maximum flow rate of $0.232903\left(\mathrm{~m}^{3} / \mathrm{s}\right)$ and $1.239422\left(\mathrm{~m}^{3} / \mathrm{s}\right)$ respectively. This new adjusted data of water discharge was considered to determine the flow duration curve needed for the assessment of agricultural canal as a possible source of small-scale hydropower.

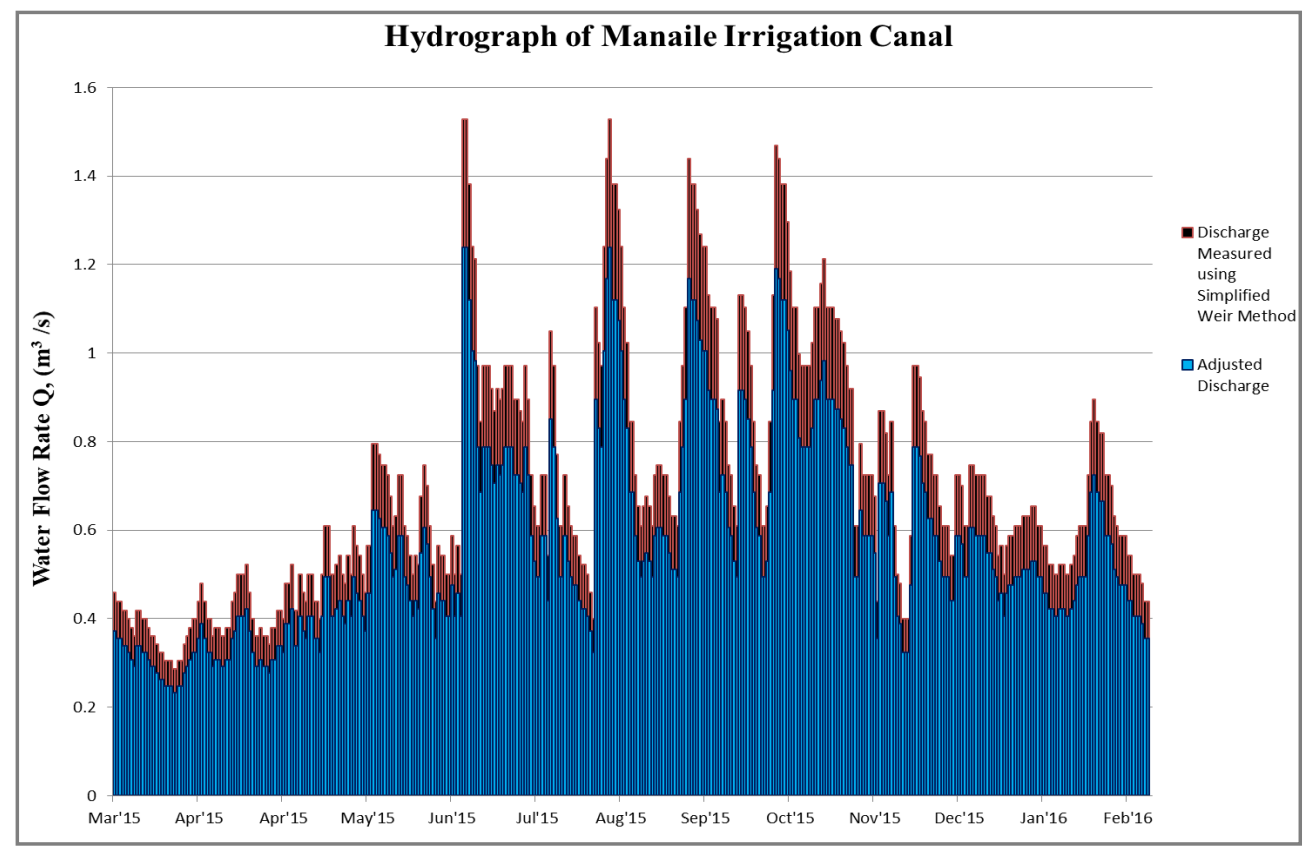

Figure 9. Water Profile of Manaile Irrigation canal

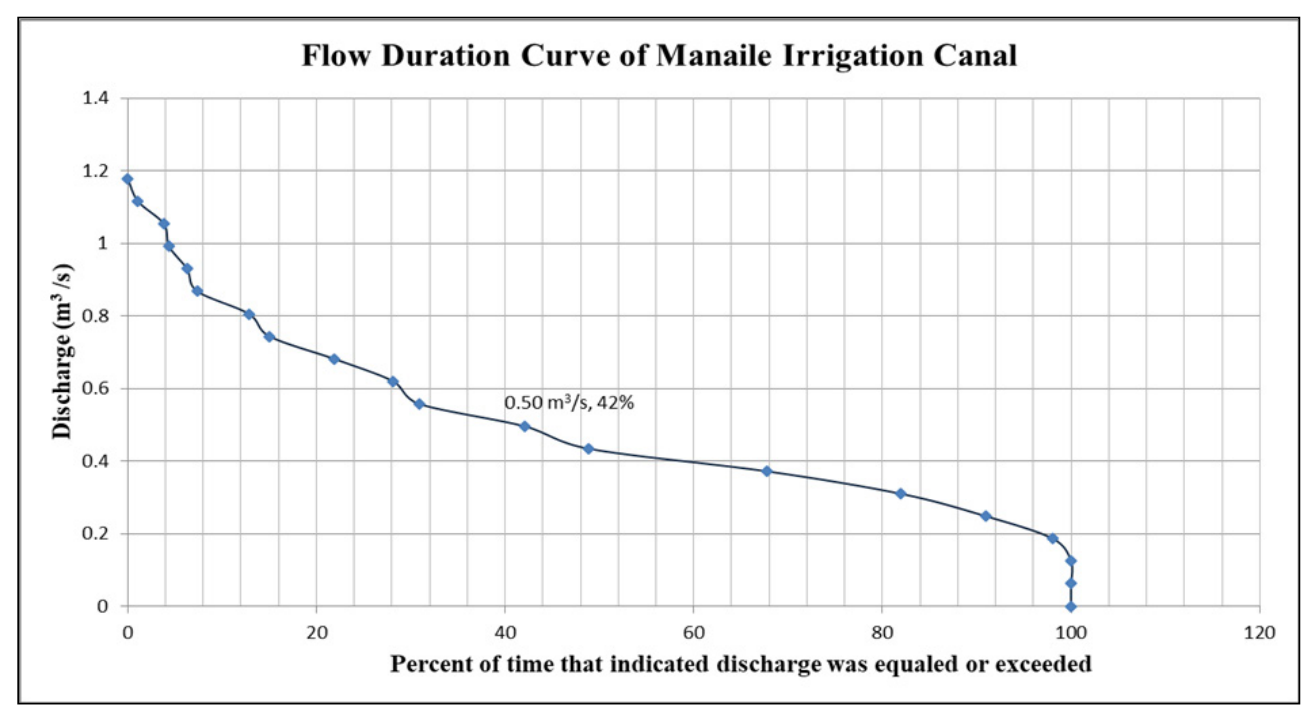

Figure 10. Flow duration curve of Manaile Irrigation 


\subsection{Flow Duration Curve}

The adjusted water profile shown in Figure 9 is converted to a flow duration curve shown in Figure 10. This shows that at $42 \%$ of the time the discharge is equaled or exceeded gives $0.50 \mathrm{~m}^{3} / \mathrm{s}$ flow rate. With the computed value of flow rate and available head, the hydropower capacity of Manaile irrigation canal $14.7 \mathrm{~kW}$, which considered to be a small-scale hydropower source (Table 2).

Table 2. Manaile Irrigation Profile

\begin{tabular}{|c|c|c|}
\hline Flow Rate, $\mathbf{Q}\left(\mathbf{m}^{\mathbf{3}} \mathbf{s}\right)$ & Head, H (meter) & Hydropower $(\mathbf{k W})$ \\
\hline 0.50 & 3.0 & 14.7 \\
\hline
\end{tabular}

\section{Conclusions}

The experiment on the comparison of common methods of discharge measurement is a procedure to determine the accuracy of each common method used for water discharge measurement. This also includes the possibility of establishing a simplified approach weir method that will overcome the disadvantage of other the common methods when continuous a series of water discharge observation is needed for an accurate assessment.

The study concludes that the use of 3-point method of current flow-meter is the most accurate method of discharge measurement. Yet, old technique, float method is still accurate and shows a negligible error in measuring water discharge.

For the more accurate assessment of water profile, multiple and series of measurement is recommended that determines hydropower capacity. Though, 3-point method of current flow meter and float method are both accurate, there are disadvantages of these methods that the simplified approach weir method can address.

The Simplified approach weir method measures only one parameter. This is the depth of water flow which can be performed even during heavy water flow and it requires no simultaneous measurement of another parameter. Unlike float and 3-point method, the simplified approach weir method could be located in the specific single point to measure the overflow depth. And with the use of the adjustment factor derived from this study, the error of simplified approach weir method could be adjusted to a true value of discharge.

\section{Acknowledgements}

The author acknowledges the support of the Engineering Research Development and Technology for the support on the conduct of case studies related to the utilization of small-scale water resources for energy generation.

\section{REFERENCES}

[1] Japan International Corporation Agency, Electric Power Development Co., Ltd., JP Design Co., Ltd. Guidelines and Manual for Hydropower Development, Philippines, Vol. 2, Small Scale Hydropower, 2011.

[2] Department of Energy, Energy Utilization Management Bureau, Japan International Corporation Agency. Micro-Hydropower Training Manual, Philippines, Vol. 1, 2009.

[3] A. Nimje, G. Dhanjode. Pico-hydro-plant for Small Scale Power Generation in Remote Villages, Journal of Environmental Science, Toxicology and Food Technology, Vol. 9, Issue 1, 59-67, 2015.

[4] G. Yadav, A.K. Chauhan. Design and Development of Pico Hydro System by using Household water supply. International Journal of Research in Engineering and Technology, Vol. 3, Issue 10, 114-119, 2014.

[5] R. Kapoor. Pico Power, A boom for Rural Electrification, Advance in Electronic and Electric Engineering, Vo. 3 No. 7, 865-872, 2013.

[6] CCLYNCH and Associates. Criteria for Proper Weir Design, https://www.cclynch.com/criteria-for-proper-weir-design/, 2012.

[7] O. Bilhan, M. E. Emiroglu. Experimental Studies in Determination of Discharge Capacity of Circular Labyrinth weirs located on a Straight Channel, International Journal of Electronics, Mechanical and Mechatronics Engineering, Vol. 6, No. 3, 1227-1239, 2016.

[8] F. M. White. Fluid Mechanics $7^{\text {th }}$ Edition, McGraw-Hill Companies Inc., 2011.

[9] S. M. Kumar. Flow Measurement methods in open channel and Modelling and Simulation of Irrigation Canals with Hydro Turbines, Quebec, 2007

[10] N. P. L. Younger, S. A. Banwart, R. S. Hedin. Mine Water: Hydrology, Pollution, Remediation, Springer Science and Business Media, 2002.

[11] Oklahoma Water Resource Board. Standard Operating Procedure for the use of Floats to determine stream discharge, 2004

[12] Ministry of Agriculture and land British Columbia. Measuring water flow. 2006

[13] P. Maher, N. Smith: Pico hydro for Village Power, 2001

[14] T. Helmenstine (2019). Online available from https://sciencenotes.org

[15] A. M. Helmenstine (2019). Online available from https://www.thoughts.com

[16] Oregon State University (2005). Online available from http://water.oregonstate.edu/streamflow/ 